\title{
Socio-spatial Segregation in the Era of Growing Economic Disparities: The Case of Tokyo
}

\section{UESUGI Masaya}

Faculty of Socio-Environmental Studies, Fukuoka Institute of Technology; 3-30-1 Wajiro-higashi, Higashi-ku, Fukuoka 811-0295, Japan.

E-mail: uesugi@fit.ac.jp

Received March 6, 2018; Accepted March 27, 2021

\begin{abstract}
Socio-economic residential segregation is an important issue of social concern and academic interest. Using population census data, we analyze the changes in residential segregation by finer occupational groups at the neighborhood level and their local spatial distribution in Tokyo from 1980 to 2005. This period was characterized by increasing economic disparities in Japan. We find that: 1) Multiple segregation indices provide evidence of some level of residential segregation by occupational groups at the neighborhood level in Tokyo. The level of residential segregation is higher for both ends of the occupational hierarchy than it is for other occupational groups. 2) While the overall level of residential segregation has continually declined, this does not necessarily translate into desegregation between opposite social groups. Furthermore, there are different patterns of changes in residential segregation, even between white- and gray-collar workers. Therefore, using finer or larger occupational groups leads to different insights on the changes in socio-spatial segregation. For the highest occupational group (managerial workers), the level of residential segregation from the lowest group was growing. However, segregation also increased from other occupational groups, except for a short period immediately following the collapse of the bubble economy in the early 1990s. Managerial workers were even more spatially concentrated in central areas of Tokyo, which were already highly concentrated.
\end{abstract}

Key words residential segregation, occupational group, managerial workers, segregation index, Tokyo

\section{Introduction}

Socio-economic residential segregation is not only a matter of academic interest but also has implications for society. This is because the socio-spatial division has the potential to impact the urban social life of residents. According to neighborhood effects research (Sampson et al. 2002; van Ham et al. 2012), a neighborhood's socioeconomic composition affects individuals' educational, economic, and health outcomes beyond their individual attributes. In Japan as well, for example, residents of neighborhoods with large income disparities have low social capital (Ichida et al. 2009). Furthermore, individuals' perceptions of trust vary by their neighborhood's occupational composition (Murayama et al. 2014). In this context, interest in socio-spatial segregation at the neighborhood scale has been growing in urban geographical studies (Maloutas and Fujita 2012; Tammaru et al. 2016; Musterd et al. 2017; van Ham et al. 2020).

Socio-economic segregation, a division in which people live based on the social and economic status of the residents, is a common characteristic of many capitalist cities. Studies cite socio-economic disparities as key factors that drive residential segregation (Watson 2009;
Reardon and Bischoff 2011; Marcińczak et al. 2015; Tammaru et al. 2016). Various statistics show that economic disparity began growing in Japan after the 1980s. In the 1980s, Japan entered a phase of historic economic expansion in which asset prices increased rapidly. However, roughly in 1991, the so-called bubble economy collapsed and the economy fell into a long-term recession that dragged on throughout the 1990s. As a result, Japan has experienced an increase in irregular employment and changes in the Japanese-style wage system such as the seniority-based system since this period. In an income redistribution survey conducted by the Ministry of Health, Labour, and Welfare, the Gini coefficient for initial income rose from 0.35 in 1981 to 0.57 in 2014. Regarding redistributed income, the Gini coefficient also increased from 0.31 in 1981 to 0.39 in 2005, although it fell slightly to 0.38 in 2014. According to data from the World Wealth and Income Database, the share of the top $1 \%$ of income earners (which also represents the magnitude of inequality) rose steadily until the early 2000s, except for a decrease immediately after Japan's bubble economy collapsed. Furthermore, another consequence of the bursting of the bubble economy was the decline in residential land prices, which increased the supply of con- 


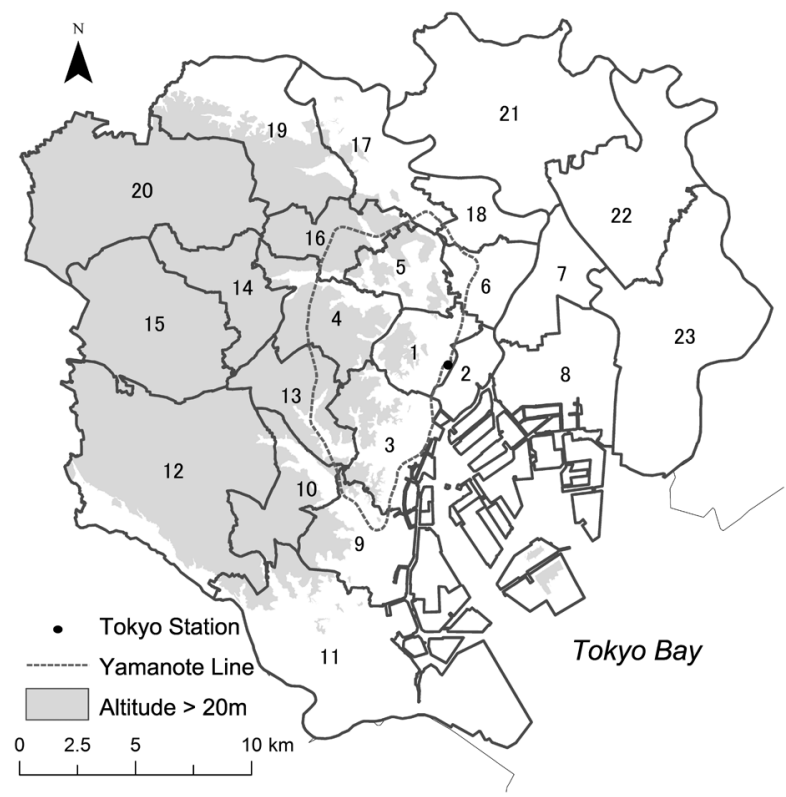

Figure 1. Study area: Tokyo wards area.

Notes: 1. Chiyoda; 2. Chuo; 3. Minato; 4. Shinjuku; 5. Bunkyo; 6. Taito; 7. Sumida; 8. Koto; 9. Shinagawa; 10. Meguro; 11. Ota; 12. Setagaya; 13. Shibuya; 14. Nakano; 15. Suginami; 16. Toshima; 17. Kita; 18. Arakawa; 19. Itabashi; 20. Nerima; 21. Adachi; 22. Katsushika; 23. Edogawa.

Source: National Land Numerical Information (Ministry of Land, Infrastructure, Transport and Tourism).

dominiums and helped in the recovery of population in the city center after the second half of the 1990s.

Therefore, we focus on the period from 1980 until 2005 , when economic disparities increased ${ }^{1}$ and quantitatively evaluate changes in the degree of residential segregation by the occupational group at the neighborhood level in Tokyo (Figure 1). As illustrated next in the Background section, many studies have examined short periods and consolidated occupational classifications into broad categories such as white-collar or middle class. Moreover, these studies seek to identify the types of spatial structures by socioeconomic status, such as zone- or sector-type distributions, rather than evaluate the degree of residential segregation or concentration of a particular social group in ways that are directly comparable across time and cities. A recent study found that the segregation level between the high- and low-income groups declined in Tokyo after the 1980s, in contrast to New York and London (van Ham et al. 2020). However, some scholars (Kurasawa and Asakawa 2004; Wakabayashi and Koizumi 2014) observed different changes in residential segregation among high-income occupational groups (white-collar workers). Thus, by evaluating the long-term dynamics of residential segregation at the neighborhood level, focusing on each specific occupational group rather than a coarse classification, and using quantitative indica- tors, this study adds to the existing literature on social areas and residential structures in Japan.

The remainder of this study is organized as follows. First, we undertake a literature review to provide a theoretical backdrop for the socio-economic segregation and empirical knowledge of our study area, Tokyo. Next, we present the data and our analytical methods. Following this, we assess the degree of residential segregation and changes over time using multiple segregation indices. Then, we discuss the changes in the local spatial patterns. Finally, we present our conclusions and future research directions.

\section{Background}

Growth in residential segregation is largely influenced by an increase in socio-economic disparities (Massey 1996; Watson 2009; Reardon and Bischoff 2011). People in the upper and lower social classes tend to live apart in cities. Therefore, greater socio-economic disparities are expected to foster greater spatial distances between these classes, leading to more extensive residential segregation. Sassen's (2001) theory of social polarization claims that global economic restructuring, particularly in global cities, has precipitated the growth of producer services and a decline in the manufacturing industry that had contributed to the creation and expansion of a robust middle class until then. Thus, the industrial structure changed; this change was in the form of the growth of both ends of the occupational hierarchy. The social polarization hypothesis suggests that there was an impact on the city's spatial structure, such as the gentrification precipitated by the redevelopment of residential and commercial facilities for higher-income residents (Sassen 2001).

Meanwhile, studies also emphasize distinguishing between social and spatial polarization (Toyoda 1999, 2007). The level of residential segregation depends on the welfare and housing regime, the institutional environment, historical profiles, immigration levels, and the level of social inequality (Maloutas and Fujita 2012; Marcińczak et al. 2015; Tammaru et al. 2016; Musterd et al. 2017; Uesugi 2019). In particular, Ueno (2008) argued that Japan has changed into a neoliberal society since the 2000s due to its accelerated deregulation of urban planning and weakened spatial redistribution policies. However, Jacobs (2005) and Waley (2013) noted that this is still different from the situation in Western countries in terms of the state's active involvement in urban redevelopment. These suggests that the impacts of external factors such as globalization and economic trends on local 
spatial structures are small in Tokyo. Instead, the existing urban spatial structure, government, and local context are likely to play significant roles in preventing the development of residential segregation. Furthermore, Japan is unique in its low level of immigration relative to Western countries and its historical circumstances, which include post-war rapid economic growth, an unprecedented bubble economy, and the subsequent recession.

This study focuses on Tokyo's urban structure which is characterized by contrasts between western and eastern areas. These are the white-collar residential districts that are spread out in sectors on the western high ground areas and the blue-collar residential districts that span the eastern low-lying areas to the southwestern outskirts where today there are many manufacturing plants (Kurasawa 1986). Since the 1980s, empirical research on Tokyo has noted that while the socio-economic polarization has progressed, the level of residential segregation is still low compared to Western countries (Jacobs 2005, 2012; Fujita and Hill 2012). For example, some scholars (Jacobs 2005, 2012; Toyoda 2007, 2011, 2012; Hashimoto 2011; Hashimoto and Asakawa 2020; Fujita and Hill 2012) have found that residential segregation progressed among municipalities or at a distance from the city center; that is, in the form of an increase in the level of income in the city center and Yamanote (high ground areas), and a decrease in peripheral districts and Shitamachi (low-lying areas) from the 1980s until the 2000s, with only a brief interruption immediately after the bubble economy burst. These studies also provide evidence on the existence of a concentric ring structure in the city center based on occupational status (Koizumi 2010; Aoi and Nakazawa 2014; Nakazawa 2016).

Residential segregation appears in a different form at the level of spatial units smaller than municipalities (Fielding 2004). Neighborhood studies show the existence of spatial patterns of sectors and concentric rings, but find that they have become more ambiguous over time (Kurasawa 1986; Kurasawa and Asakawa 2004; Wakabayashi and Koizumi 2014). However, these studies focus on identifying the types of spatial patterns from an ecological perspective. Only a few studies have quantified existing levels of residential segregation to assess the extent of concentration of a particular occupational group in a particular neighborhood. For example, based on a global segregation index, van Ham et al. (2020) observed decreasing residential segregation between the highand low-income groups in Tokyo. Koizumi (2010, 2015) and Koizumi and Wakabayashi (2015) used Moran's I to measure the spatial concentration of specific groups and found that white-collar and blue-collar workers have statistically significant concentrations in Tokyo's metropolitan area, but that the level of these concentrations is declining slightly. The authors concluded that while the groups' uneven spatial distributions are becoming less severe, residential segregation by occupational structure is still prevalent in the metropolitan area. These studies categorized each occupational group into white- or blue-collar workers. In contrast, other studies using finer occupational groups found that professional and technical workers maintained a sector-type spatial pattern, while managerial workers had shifted to a concentriczone-type spatial pattern, even though both were categorized as white-collar workers (Kurasawa and Asakawa 2004; Wakabayashi and Koizumi 2014). Therefore, residential segregation within broad categories (i.e., white-, gray-, and blue-collar workers) should be investigated by breaking these categories into each occupational group. Researchers in other countries have also reported similar observations. Cunningham and Savage (2017) found that most elite classes, such as senior managers, were concentrated in London's center, and that they were becoming increasingly segregated from other middle classes such as professionals. This study asserts that particular attention should be given to segregation at the top end of the class structure.

Further, such demographic changes occurring alongside gentrification have the potential to lead to residential segregation. In Tokyo, where land prices dropped after the collapse of the bubble economy, white-collar workers stood out as the group with an excessive influx into the city center (Miyazawa and Abe 2005; Koizumi 2015; Nakazawa 2016). In the 2000s, many high-rise residential complexes were completed in the bay area, which had originally been a peripheral area. Many managers, technicians, and skilled professionals moved into that area. Studies pointed out that gentrification accompanied the residents' upward shift in socio-economic composition due to the displacement of former residents (Koizumi 2010; Hashimoto 2011; Fujitsuka 2013; Koizumi and Wakabayashi 2015; Nakazawa 2016). Other studies noted the occurrence of "the new-built gentrification" (Lützeler 2008) or "time-lagged gentrification" (Hashimoto and Asakawa 2020) that did not directly accompany the displacement of former residents. Kubo (2020) observed that one of the results of the neoliberal urban policies from the late 1990s was the conspicuous spatial disparities between a thriving housing market in the city center and slumped market outer districts. Once the neighborhood values increase in gentrified districts, the process of gen- 
trification is further promoted. Based on the extensive literature, socio-spatial segregation during the study period should be investigated and understood within the context of the gentrification process.

\section{Data and Methods}

Our study area comprises Tokyo's wards area, which consists of 23 wards (Figure 1; hereafter referred to as Tokyo). Koizumi and Wakabayashi (2015) had cautioned against the technical problems regarding urban spaces and residential structures; the comparability of the variables and spatial units used for analysis, and the objectivity involved in interpreting spatial patterns. We took the following measures to avoid these types of problems.

Income and occupation can be cited as indicators of the socio-economic characteristics of residents, as discussed in the previous section; here, we focused on occupation. Although income and occupation do not necessarily correspond with one another, one aspect of spatial inequality in Tokyo based on social status is clearly occupation. The number of employed workers by occupation living in small-area units was gathered from a population census conducted once every five years. In addition, since occupational groups are often used in research in Japan and elsewhere (Fielding 2004; Kurasawa and Asakawa 2004; Fujita and Hill 2012; Wakabayashi and Koizumi 2014; Marcińczak et al. 2015; Tammaru et al. 2016; van Ham et al. 2020), this classification is advantageous in terms of comparability between these studies.

Occupational classifications fall under the following nine types, ${ }^{2}$ excluding unclassifiable occupations: managerial workers (MGR), professional and technical workers $(\mathrm{P} \& \mathrm{~T})$, clerical workers (CLE), sales workers (SAL), service workers (SER), security workers (SEC), agricultural, forestry and fisheries workers (AGR), workers in transport and communications occupations (T\&C) and production process workers and laborers (PPW). ${ }^{3}$ Changes in occupational compositions over the past 25 years have been straightforward (Figure 2). The numbers and proportions of P\&T have increased with advancing globalization and the sophistication of operations. Meanwhile, the numbers and proportions of MGR have decreased due to increased corporate restructuring. Nevertheless, MGR and P\&T together represent approximately $20 \%$ of the workers, and if CLE is included, this group accounts for just under half of the total number of workers. Meanwhile, due to increasing post-industrialization and a hollowing out of domestic industries, PPW shows a consistent decreasing trend and accounts for approximately

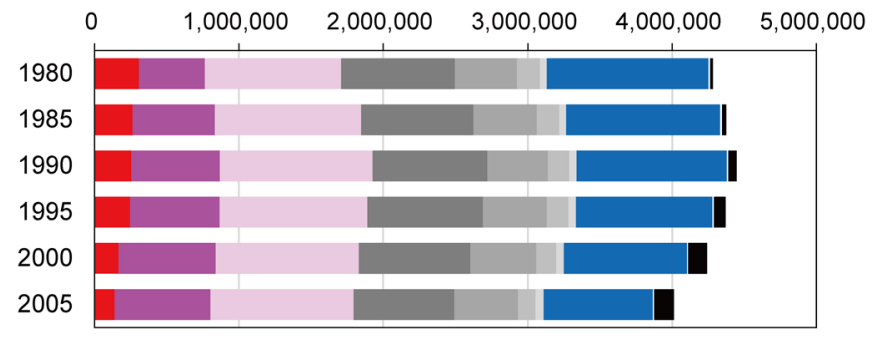

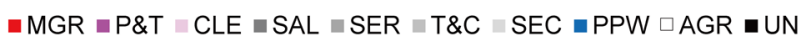

Figure 2. Number of workers by occupational group in Tokyo wards area: 1980 to 2005.

Source: Population Census (Ministry of Internal Affairs and Communications)

$20 \%$ of the workers. In most analyses, we particularly pay attention to seven occupational groups except for SEC and ARG, because these two groups account for a small percentage.

As for the spatial units of analysis, we gave emphasis to the comparability over time and used the grid square unit (half grid square), which does not change over time. Although administrative boundaries at the small-area level (e.g., cho district) have some advantages, they change over time. One grid unit is approximately $500 \mathrm{~m}$ square and is equal to the neighborhood scale.

In terms of analytical methods, multiple indicators were used to quantify the degree of residential segregation in each occupational group. Duncan and Duncan's (1955) dissimilarity index $(D I)$ and segregation index (SI) have been used in many studies. ${ }^{4}$ DI shows the extent to which two groups living in the same city are spatially separated. The higher the value, the greater the level of residential segregation; if there is an even distribution, the value is 0 ; if the two groups are completely separated, then the value is 1 . SI expresses how unevenly one group lives compared to the other groups. As such, a higher SI value equates to a greater level of residential segregation.

The above indices are calculated for a specific occupation (one or a combination of two). Thus, here, we first measured the multigroup residential segregation to evaluate the level of overall residential segregation. Reardon and Firebaugh (2002) introduced several measures of multigroup segregation: the multigroup dissimilarity index $(D)$, the multigroup Gini index $(G)$, the information theory index $(H)$, and the squared coefficient of variation $(C) .^{5} D$ is the generalized form of binary $D I$ mentioned above for multiple groups. $G$ is the weighted sum of the weighted average absolute difference between the groups' proportions for all pairs of districts. $H$ is the weighted average deviation of the within-district population diversity (entropy) from the diversity of the total 
population. $C$ can be interpreted as a measure of the variance of the ratio of a proportion in a group to the proportion of a group in a district (Reardon and Firebaugh 2002). These indices vary between 0 and 1 (maximum segregation) owing to standardization to the maximum possible value. Here, we employed the Geo-Segregation Analyzer software (Apparicio et al. 2014) to calculate these indices based on the aforementioned nine types of occupational groups. ${ }^{6}$

The above-mentioned segregation measures are global indices and are aspatial, hence, they cannot simply capture local variation (Brown and Chung 2006). Therefore, to illustrate the local spatial patterns of residential segregation and how they change over time, a location quotient (LQ) was used. ${ }^{7}$ Brown and Chung (2006) presented $L Q$, which treats each neighborhood independently indicating single-unit concentration, and Local Moran's $I$, which identifies clusters based on its adjacency requirement, as local indicators for segregation studies. However, we used $L Q$ at this stage to illustrate the degree of concentration of a group in a particular neighborhood, including outliers that indicate spatial trends. $L Q$ is the ratio of the percentage of a certain occupational group in a certain district to the percentage of that group within the entire city. If the value is greater than 1 , then the group has a higher concentration in that district.

Lastly, we used the Getis-Ord Gi* (Ord and Getis 1995) statistic to highlight areas where gentrification has possibly been documented in previous research. ${ }^{8}$ Changes in social composition within neighborhoods can be significant for gentrification. Therefore, clusters with notable changes in $L Q$ were identified. Focusing on major players in gentrification MGR and P\&T, we mapped the clustering of districts with a relatively high (or low) breadth of variation compared to the surrounding districts. These processes were conducted using ESRI ArcGIS, while the spatial patterns of $L Q$ were visualized using $\mathrm{R}$ ( $\mathrm{R}$ Core Team 2018).

\section{Evaluating Residential Segregation Based on Segregation Indices}

Table 1 summarizes the overall level of residential segregation across multiple occupational groups in Tokyo from 1980 to 2005 . This is represented by the changes in indices $D, G, H$, and $C$. First, we find that the values tended to decline continuously over time, and this tendency was consistent across all the indices. Although the differences vary depending on the index, the decreases ranged from $25 \%(G)$ to $38 \%(C)$ over 25 years. Further, the downward trend is similar in that the values have become more moderate since 1995. Nevertheless, economic disparity has grown throughout Japan since 1980. There were significant changes to the socio-economic background in this period, including the bubble economy, its collapse, and the subsequent long economic downturn. Nevertheless, residential segregation by occupational groups has continually become more relaxed; in other words, there is a tendency to become socially mixed.

Second, we focus on residential segregation in specific occupations. SI shows how far one occupational group lives from other occupational groups. Figure 3 shows the variations in SI trends by occupational group. We find 1) both the higher (MGR and P\&T) and lower (PPW) occupational hierarchies have higher levels of residential segregation. This has changed little even over the years, and 2) the segregation levels of most occupational groups are continually decreasing. This is in line with the downward trend of the overall residential segregation level mentioned before. However, MGR and T\&C show exceptional trends.

Regarding the first point on segregation by occupation, since a close relationship exists between social (i.e., occupational hierarchy) and spatial distances (i.e., level of residential segregation), residential segregation by occupational groups exists in Tokyo. Cities in Western countries also exhibit this tendency of the greatest level of residential segregation being at the opposite ends of the social hierarchy (Duncan and Duncan 1955; Morgan 1975). Therefore, it seems that Japan and Western countries have similar properties in terms of a socio-spatial division. However, Western research pointed out that the highest social group had the highest degree of residential segregation, while in Tokyo, the lowest occupational group (PPW) had a higher degree of segregation. This indicates a difference from segregation in Western coun-

Table 1. Changes in multigroup segregation indices

\begin{tabular}{ccccc}
\hline & $\begin{array}{c}\text { Multigroup } \\
\text { dissimilarity } \\
\text { index }(D)\end{array}$ & $\begin{array}{c}\text { Multigroup } \\
\text { Gini index }(G)\end{array}$ & $\begin{array}{c}\text { Information } \\
\text { theory index }(H)\end{array}$ & $\begin{array}{c}\text { Squared } \\
\text { coefficient of } \\
\text { variation }(C)\end{array}$ \\
\hline 1980 & 0.165 & 0.228 & 0.038 & 0.028 \\
1985 & 0.156 & 0.215 & 0.036 & 0.027 \\
1990 & 0.147 & 0.203 & 0.033 & 0.025 \\
1995 & 0.136 & 0.188 & 0.029 & 0.021 \\
2000 & 0.130 & 0.181 & 0.027 & 0.019 \\
2005 & 0.124 & 0.174 & 0.025 & 0.018 \\
\hline
\end{tabular}

Source: Population Census (Ministry of Internal Affairs and Communications). 


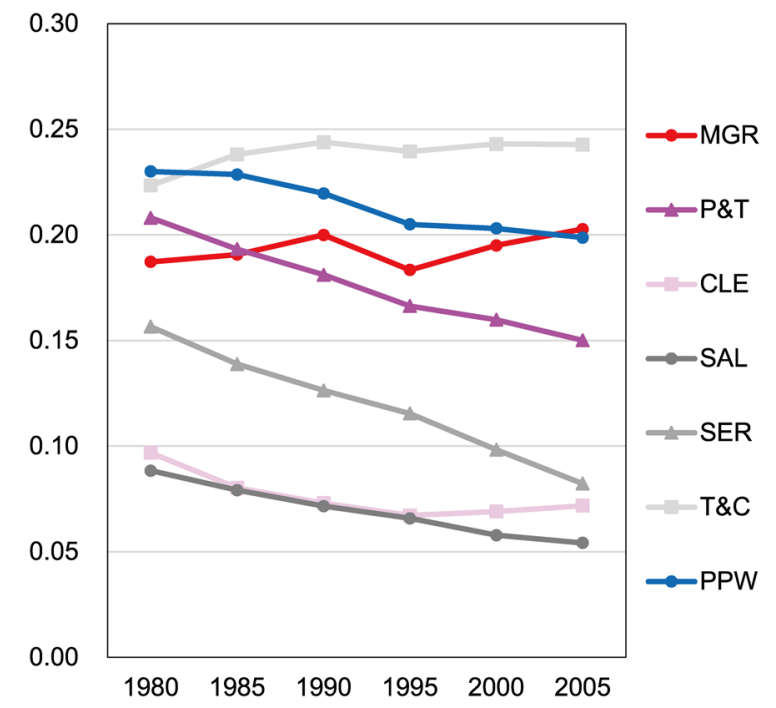

Figure 3. Trends in Segregation Index $(S /)$ by occupational group.

Source: Population Census (Ministry of Internal Affairs and Communications).

tries, at least until 2005. As for the change, there were no significant changes in SI rank over 25 years; thus, the structure of residential segregation has mostly remained the same since 1980 .

The second point is also related to the first, in that it emphasizes differences in the changing patterns of segregation by specific occupational groups, especially MGR. This group has been increasingly spatially segregated from others, except for the time immediately after the collapse of the bubble economy in 1991. Similar to MGR, P\&T also represents white-collar workers but had a higher residential segregation level than MGR in 1980. However, unlike MGR, P\&T's segregation has continued to decrease greatly. Residential segregation for CLE, which had about half the residential segregation level of MGR and P\&T in 1980, also declined until 1995. Gray-collar groups also showed different trends by occupational groups: SAL and SER had a low level of residential segregation, which has become even lower; however, T\&C's level of residential segregation rose in the 1980s and remained at a high level. In addition, while the scale of PPW and its level of residential segregation have decreased, PPW has maintained a higher level compared to other occupational classifications.

Some characteristics of residential segregation between the two occupational groups that could not be understood by $S I$ alone are evident from the DI in Figure 4. For example, the highest occupational group MGR experienced the greatest increase in residential segregation from T\&C and PPW, followed by the gray-collar groups SER and SAL, and then the white-collar groups CLE and
P\&T. In terms of change, MGR has been increasingly segregated not only from the lowest occupational group PPW but also from all other occupational groups after 1995, except for P\&T. In addition, although the SI of CLE has not changed substantially since 1995, DI shows an increased separation from MGR and PPW at the opposite ends of the occupational hierarchy. Meanwhile, the degree of separation from P\&T and the gray-collar groups SER and SAL has decreased. These results provide evidence of the notable relationship between social and spatial distances.

\section{Mapping Local Spatial Patterns of Residential Segregation}

Here, $L Q$ indicates the local level of spatial concentration or dispersion of occupational groups within the city. Figure 5 shows the spatial distribution of $L Q$ for seven occupational classifications at four points in time: 1980, 1990, 2000, and 2005.

The distribution of the upper white-collar groups' MGR and P\&T shows a clear concentration in western Tokyo. However, differences between the two groups are present. For MGR, the number of districts with high $L Q$ is increasing in the central area, showing a trend of further concentration in the city center. The spatial distribution has shifted from a sector shape to a concentric shape, similar to the findings of previous research (Kurasawa and Asakawa 2004; Wakabayashi and Koizumi 2014). Although the number and ratio of MGR has decreased since 1980, their places of residences have become more selective. In contrast, for P\&T, on the one hand, many districts where $L Q$ exceeded 1.5 in the west in 1980 had almost disappeared by 2005; on the other hand, the $L Q$ of many districts in the east rose. In addition, the neighborhoods from Chuo Ward to Koto Ward have a greater concentration of districts with $L Q$ exceeding 1.1. In 1980, there were low concentrations of the white-collar group in these areas despite the short distance to the city center. Therefore, they may have had the potential for gentrification.

Some of the above findings can also be verified by the change in the number of districts by $L Q$ class, as shown in Table 2. The higher the proportion of districts in which $L Q$ exceeds 1.5 (high concentration) or where $L Q$ is lower than 0.5 (low concentration), the higher the level of residential segregation. There is also a greater degree of mixing, which is consistent with the average for the whole city, with more districts ranging from 0.9 to 1.1. As of 1980, MGR's $L Q$ exceeded 1.5 in $17 \%$ of the districts, and 

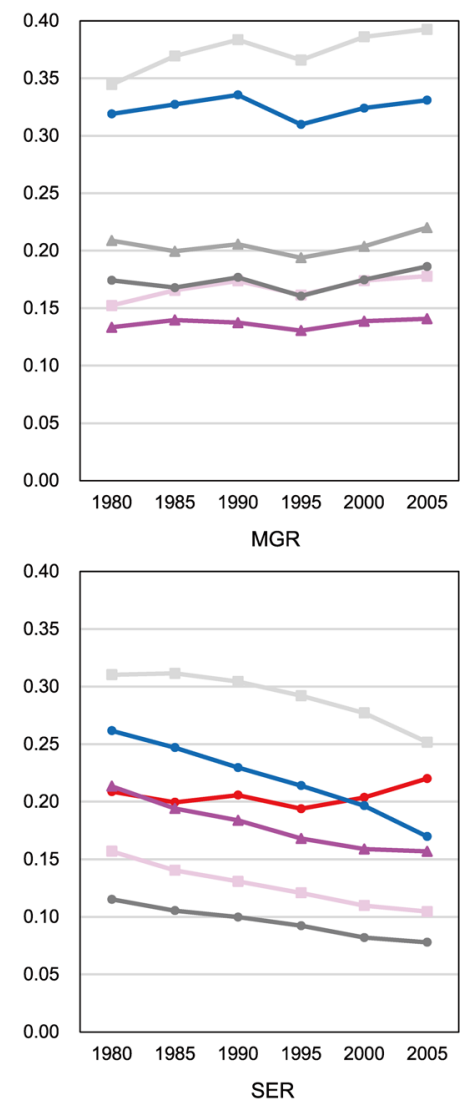
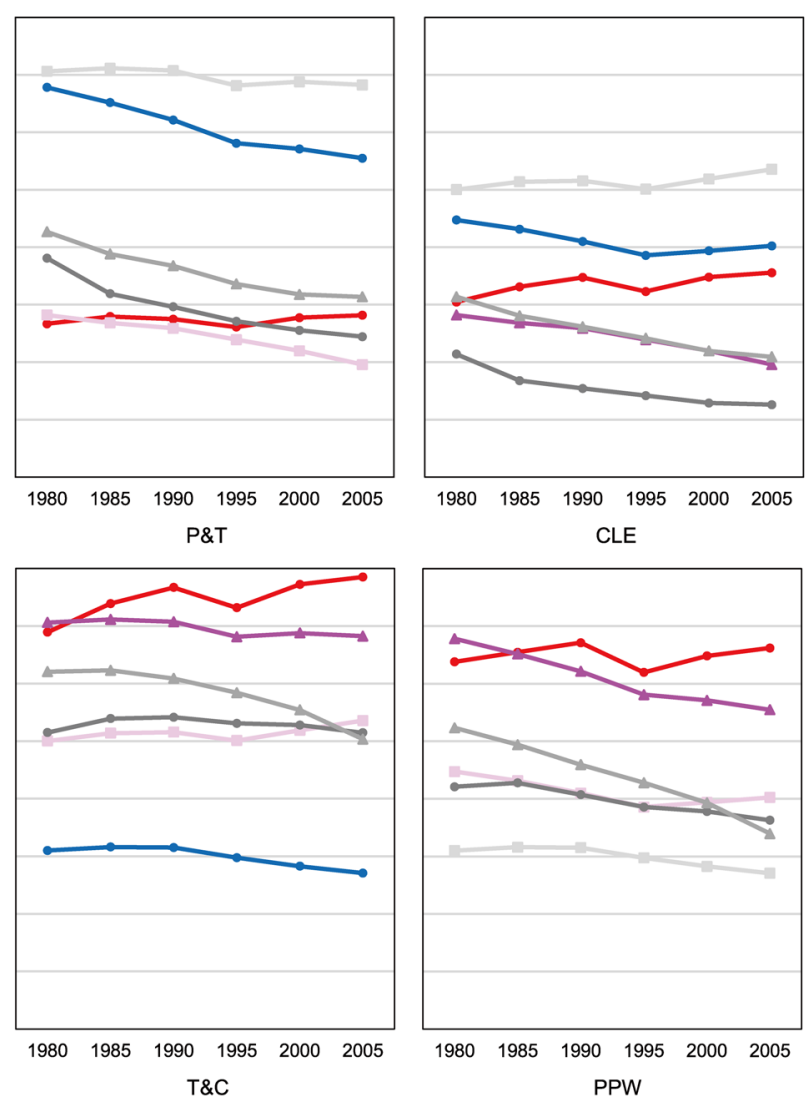

CLE

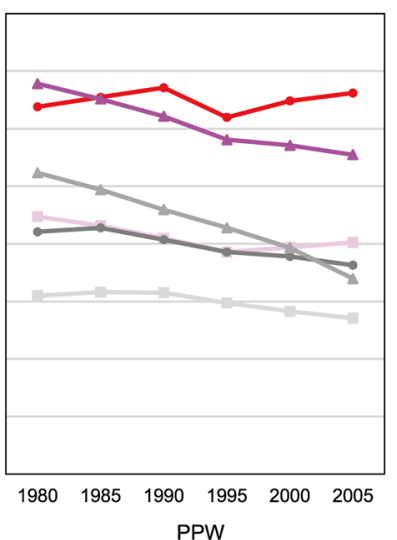

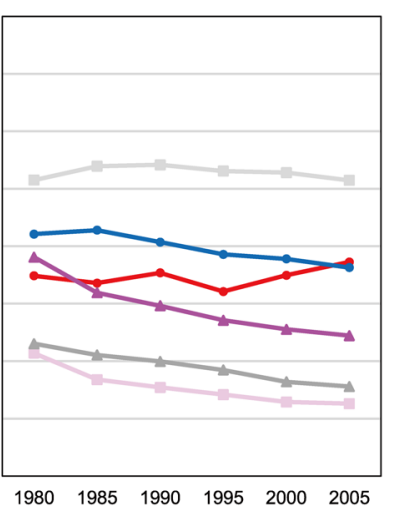

SAL

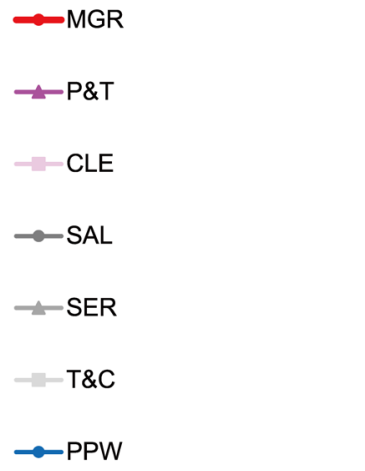

$\leadsto$ PPW

Figure 4. Trends in Dissimilarity Index (DI) by occupational group.

Source: Population Census (Ministry of Internal Affairs and Communications).

the similar percentage was maintained in 2005; however, for P\&T, the percentage of districts with $L Q$ exceeding 1.5 has decreased by a third over the past 25 years. Instead, the percentage of districts where $L Q$ is 0.9 to 1.1 has doubled. Furthermore, the percentage of districts with an $L Q$ of 1.1 to 1.5 is increasing. For CLE, SAL, and SER, there is a high level of mixing with $40-60 \%$ of the districts having an $L Q$ of 0.9 to 1.1. This supports the results of the indexbased investigation for residential segregation obtained in the previous section.

For PPW, in contrast to the white-collar group, districts with high $L Q$ are concentrated in the peripheral and eastern parts of the city. These districts also overlap with traditional industrial areas and large amounts of public housing estates. This reflects the regional characteristics of closer proximity of housing and places of work. Since the proportions of PPW have remained high here even after the decline of the manufacturing industry, Kurasawa and Asakawa (2004) pointed to the existence of the "left behind" people. However, as shown by the continuous downward trend of PPW's SI and decreasing number of high $L Q$ districts, particularly along railway lines, residential segregation seems to be declining.

Finally, to further highlight the changes over time and the characteristics of gentrification pointed out above, we extracted areas with remarkable changes in LQ. Figure 6 shows the hot and cold spots for changes in the level of $L Q$ for 1980-1990, 1990-2000, and 2000-2005. The corresponding maps also show the differences in residential segregation for MGR and P\&T. First, in the 1980s, when the price of land in the city center skyrocketed during the bubble economy period, the MGR's rising $L Q$ was notable across the three central wards of Chiyoda, Chuo, and Minato, as well as Shibuya. This is considered a relative increase in $L Q$ due to the large decrease in other occupational groups, including P\&T, given that the overall population is decreasing. During this period, in eastern Tokyo, particularly in Koto Ward and Edogawa Ward, there was a clustering of districts where the $L Q$ of $P \& T$ rose along the railway lines with the opening and expansion of subways as well as earlier residential development sites. These areas overlap with areas in which the $L Q$ for PPW exceeded 1.5, in the 1980s.

After the bubble economy collapsed in 1991, the population in most wards declined through the early 1990s. However, it began increasing in the late 1990s. This trend was especially remarkable in the three central wards. During this period, areas with a characteristic increase in MGR's $L Q$ were located around Chiyoda Ward and along the Yamanote Line (a railway loop line connecting most 

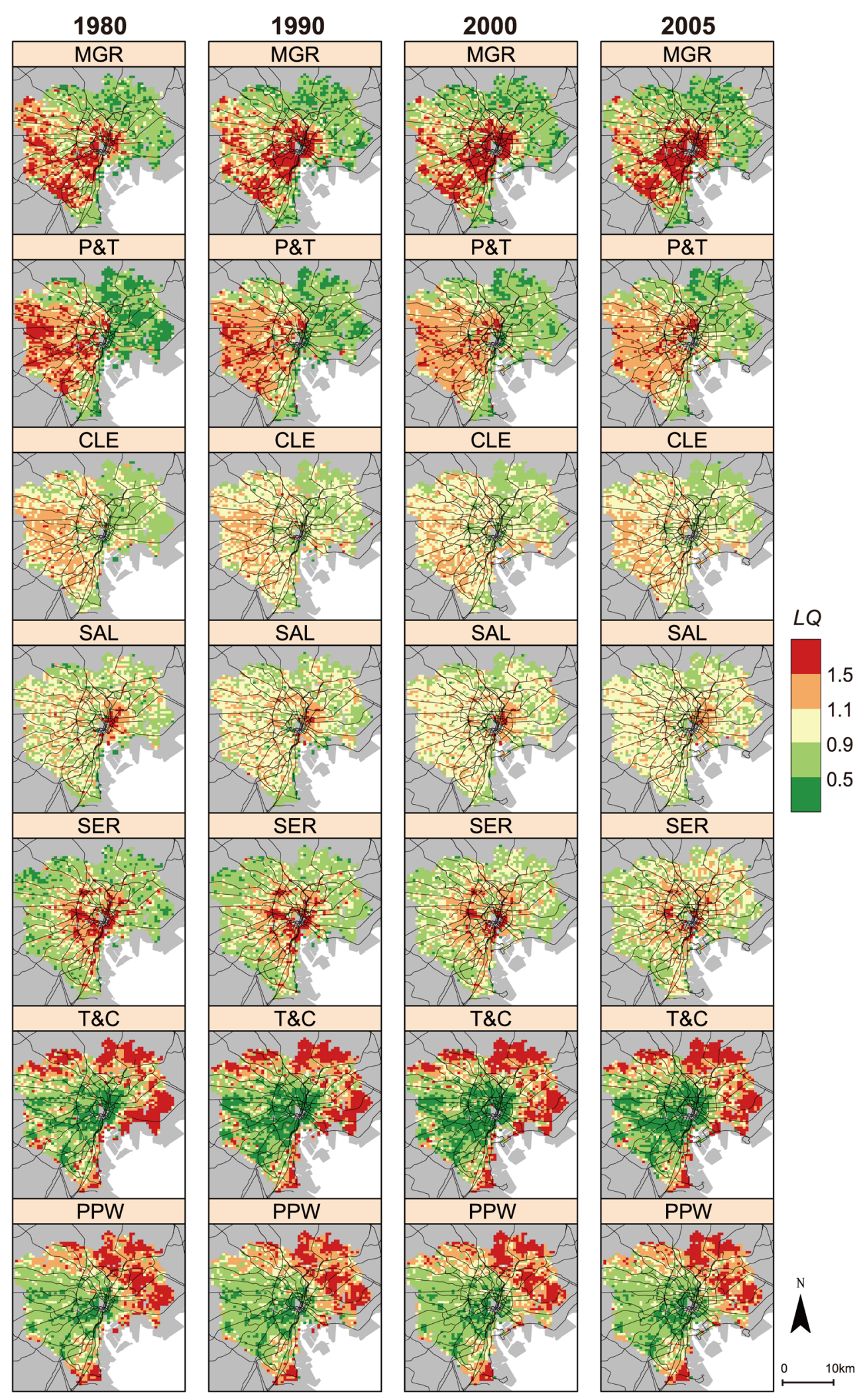

Figure 5. Distribution of Location Quotient (LQ) of occupational group: 1980 to 2005.

Note: Districts with fewer than 100 workers are excluded from mapping (gray-colored) Source: Population Census (Ministry of Internal Affairs and Communications).

major stations in Tokyo). However, in the period from 1990-2000, cold spots appeared in Minato Ward, where there were hot spots in the 1980s. This might have caused a decline in the residential segregation of MGR in the early 1990s, as shown in the previous section. According to Yabe (2003), in the early 1990s, the largest supply of housing in Minato Ward was relatively inexpensive public housing. This characteristic was different from both 
Table 2. Changes in the number of districts by Location Quotient (LQ) of occupational groups

\begin{tabular}{|c|c|c|c|c|c|}
\hline Occupational group & $\angle Q$ & 1980 & 1990 & 2000 & 2005 \\
\hline \multirow[t]{5}{*}{ MGR } & $<0.5$ & $11 \%$ & $14 \%$ & $13 \%$ & $13 \%$ \\
\hline & $0.5-0.9$ & $38 \%$ & $35 \%$ & $39 \%$ & $39 \%$ \\
\hline & $0.9-1.1$ & $14 \%$ & $15 \%$ & $14 \%$ & $13 \%$ \\
\hline & $1.1-1.5$ & $20 \%$ & $18 \%$ & $16 \%$ & $17 \%$ \\
\hline & $\geq 1.5$ & $17 \%$ & $18 \%$ & $18 \%$ & $18 \%$ \\
\hline \multirow[t]{5}{*}{$P \& T$} & $<0.5$ & $22 \%$ & $13 \%$ & $10 \%$ & $8 \%$ \\
\hline & $0.5-0.9$ & $27 \%$ & $34 \%$ & $35 \%$ & $34 \%$ \\
\hline & $0.9-1.1$ & $11 \%$ & $13 \%$ & $16 \%$ & $19 \%$ \\
\hline & $1.1-1.5$ & $24 \%$ & $30 \%$ & $33 \%$ & $33 \%$ \\
\hline & $\geq 1.5$ & $16 \%$ & $10 \%$ & $6 \%$ & $5 \%$ \\
\hline \multirow[t]{5}{*}{ CLE } & $<0.5$ & $2 \%$ & $2 \%$ & $2 \%$ & $2 \%$ \\
\hline & $0.5-0.9$ & $33 \%$ & $27 \%$ & $26 \%$ & $26 \%$ \\
\hline & $0.9-1.1$ & $36 \%$ & $50 \%$ & $52 \%$ & $50 \%$ \\
\hline & $1.1-1.5$ & $27 \%$ & $21 \%$ & $20 \%$ & $22 \%$ \\
\hline & $\geq 1.5$ & $1 \%$ & $1 \%$ & $1 \%$ & $1 \%$ \\
\hline \multirow[t]{5}{*}{ SAL } & $<0.5$ & $4 \%$ & $3 \%$ & $2 \%$ & $2 \%$ \\
\hline & $0.5-0.9$ & $34 \%$ & $27 \%$ & $22 \%$ & $21 \%$ \\
\hline & $0.9-1.1$ & $42 \%$ & $49 \%$ & $59 \%$ & $61 \%$ \\
\hline & $1.1-1.5$ & $18 \%$ & $20 \%$ & $16 \%$ & $15 \%$ \\
\hline & $\geq 1.5$ & $2 \%$ & $1 \%$ & $1 \%$ & $1 \%$ \\
\hline \multirow[t]{5}{*}{ SER } & $<0.5$ & $9 \%$ & $4 \%$ & $3 \%$ & $3 \%$ \\
\hline & $0.5-0.9$ & $49 \%$ & $47 \%$ & $39 \%$ & $33 \%$ \\
\hline & $0.9-1.1$ & $17 \%$ & $22 \%$ & $32 \%$ & $39 \%$ \\
\hline & $1.1-1.5$ & $17 \%$ & $19 \%$ & $21 \%$ & $22 \%$ \\
\hline & $\geq 1.5$ & $9 \%$ & $7 \%$ & $4 \%$ & $3 \%$ \\
\hline \multirow[t]{5}{*}{$T \& C$} & $<0.5$ & $17 \%$ & $23 \%$ & $23 \%$ & $23 \%$ \\
\hline & $0.5-0.9$ & $30 \%$ & $28 \%$ & $27 \%$ & $29 \%$ \\
\hline & $0.9-1.1$ & $14 \%$ & $10 \%$ & $12 \%$ & $11 \%$ \\
\hline & $1.1-1.5$ & $17 \%$ & $17 \%$ & $15 \%$ & $15 \%$ \\
\hline & $\geq 1.5$ & $23 \%$ & $23 \%$ & $23 \%$ & $22 \%$ \\
\hline \multirow[t]{5}{*}{ PPW } & $<0.5$ & $9 \%$ & $11 \%$ & $10 \%$ & $11 \%$ \\
\hline & $0.5-0.9$ & $36 \%$ & $36 \%$ & $37 \%$ & $37 \%$ \\
\hline & $0.9-1.1$ & $12 \%$ & $13 \%$ & $14 \%$ & $14 \%$ \\
\hline & $1.1-1.5$ & $22 \%$ & $23 \%$ & $22 \%$ & $22 \%$ \\
\hline & $\geq 1.5$ & $20 \%$ & $17 \%$ & $17 \%$ & $16 \%$ \\
\hline
\end{tabular}

Source: Population Census (Ministry of Internal Affairs and Communications).

periods: when private rental housing was the main supply before that and when there was a rapid increase in the sale of private condos after that. Furthermore, hot spots were observed in the Tsukuda district, just southeast of Tokyo Station. In this district, to encourage the population to return to the city center in the late 1980s, public and private organizations redeveloped factories and warehouse sites. One of these projects included a super highrise group of apartments called "River City 21." Although a social mix that included public housing was planned for the housing complex, many residents were MGR and P\&T (Sonobe 2001). Besides this district, there was a prominent increase in $\mathrm{P} \& \mathrm{~T}$ in the eastern part of Tokyo with newly built subway lines in the 1980s. A reduction in the $L Q$ of the blue-collar PPW, especially along the eastern railway line, implied that the composition of occupational structures in the neighborhoods was changing.

In the 2000s, when the population return to the city center continued, there were clear differences in the districts with an increase in $L Q$ between MGR and P\&T. The former was seen in the areas extending from the city center to the southwestern part of Minato Ward, particularly along the Yamanote Line. The latter was more evident in the eastern area adjacent to the city center. The hot spot areas for MGR occurred in areas already clustered with high $L Q$ of MGR. Moreover, this concentration was further strengthened in the 2000s, implying that the level of residential segregation had further increased. However, with redevelopment, the hot spot areas for P\&T extended into the bay area. In 2000, in the neighborhoods on the eastern side of Tokyo Station, there was an upward change in the occupational composition of P\&T. There were many districts where P\&T's $L Q$ was once 0.9 or less. This seems to have contributed greatly to the desegregation. Consistent with the observation that the Gini coefficient for income inside the Shitamachi areas increased from the late 1990s to the early 2000s (Hashimoto 2011), it seems that residents from diverse backgrounds were mixing. As represented by the Act on Special Measures Concerning Urban Renaissance of 2002, the 2000s were an era of urban revitalization through the deregulation of urban planning. The Japanese and the Tokyo metropolitan governments were united in promoting redevelopment through private investment. In Tokyo, the areas designated for accelerated urban renewal were concentrated in a limited area extending from central Tokyo to the bay area, where it overlapped with areas of increasing $L Q$ of MGR and P\&T, as noted before. One example of this impact can be seen in the Minato district of Chuo Ward. Here, very expensive apartments were built after residences or factories had been abandoned because of soaring land prices during the bubble economy in the 1980s (Fujitsuka 2013). In particular, for P\&T, the changes that have occurred around the city center since 2000 have been significant. For example, Miyazawa and Abe (2005) observed that from the late 1990s, there have been quantitative and qualitative changes in the scales of neighborhoods. These changes began manifesting in response to the returning populations' choice of residence in the city center, depending on their economic power and lifestyle. 


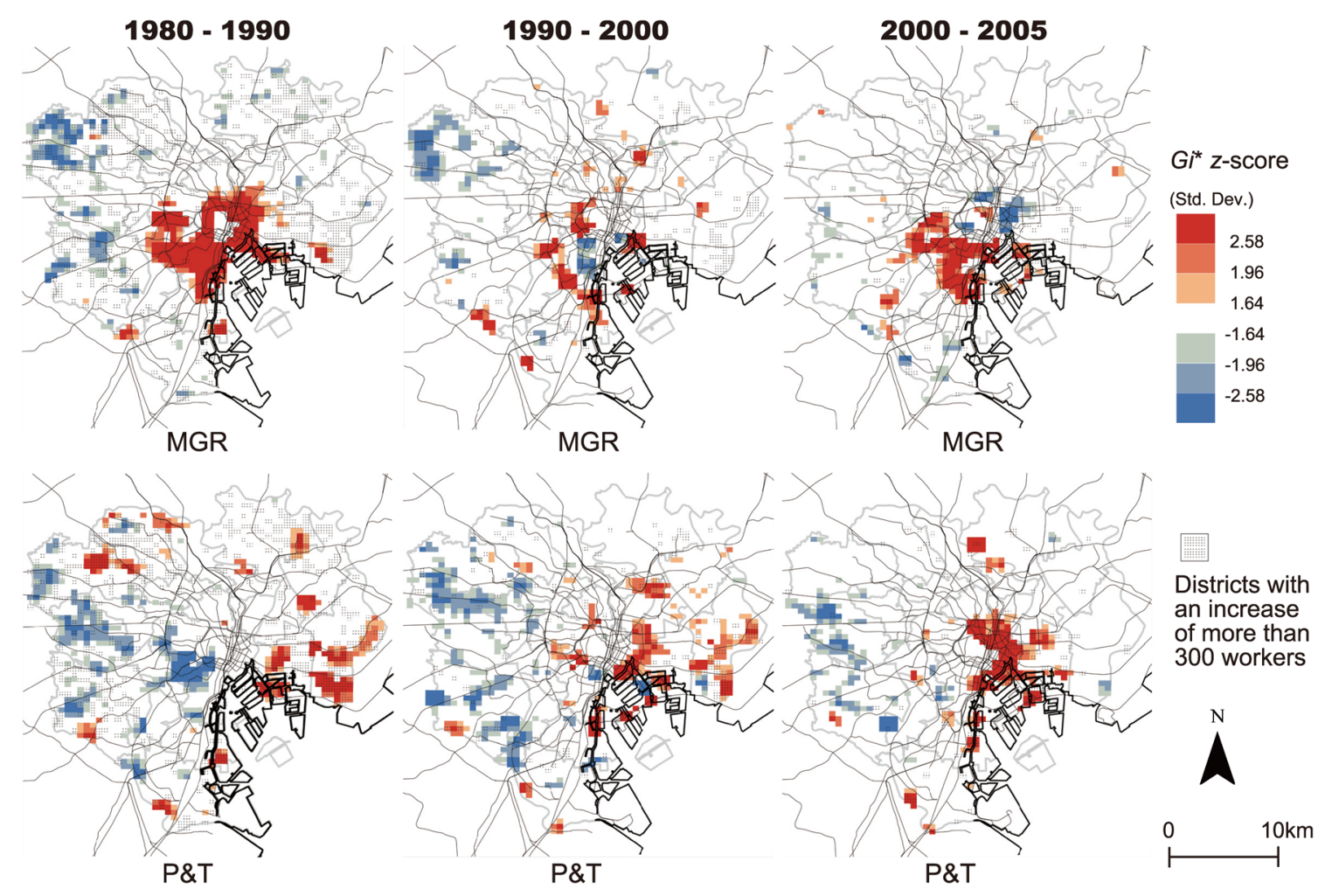

Figure 6. Clusters of changes in Location quotient (LQ) of MGR and P\&T: 1980 to 1990, 1990 to 2000 and 2000 to 2005. Source: Population Census (Ministry of Internal Affairs and Communications).

\section{Conclusions}

We analyzed the changing residential segregation by occupational groups at the neighborhood level and its local spatial pattern in Tokyo from 1980 to 2005. This is the period when economic disparities increased in Japan. The fact that the level of residential segregation is higher for both ends of the occupational hierarchy than it is for other occupational groups shows that there is an important relationship between the spatial distance represented by the level of residential segregation and the social stratification represented by occupational groups. In this sense, there is a certain level of socio-economic residential segregation in Tokyo. The advantage of using both traditional and common residential segregation indices is that it enables a comparison of Tokyo's level of segregation with other cities. Recent international comparative studies (Tammaru et al. 2016; Musterd et al. 2017) compared the degree of residential segregation between opposite social groups (managers and elementary occupations) in 13 European capitals over the first decade of the 21st century. The DI obtained from different spatial units and occupational categories should be compared with care. However, given that the DIs between MGR and PPW in Tokyo are between 0.31 to 0.34 (Figure 4), the level can be modest or slightly higher than that of European cities but lower than London and Madrid. ${ }^{9}$
Interestingly, the overall level of residential segregation has continually declined at the neighborhood level despite the disparities in growth and economic fluctuations since the 1980s. This result, based on segregation measures by multiple groups, is consistent to the findings of van Ham et al. (2020) based on the index of segregation between the opposite ends of the aggregated occupational groups. However, the present study highlights that residential segregation has progressed in some respects, based on a more detailed occupational classification: managerial workers have been increasingly segregated from other occupational groups and professional/technical workers also have been spatially segregated at the micro-scale in the process of gentrification regardless of the declining macro-scale segregation measures.

Overall desegregation does not translate into a reduced level of segregation between specific occupational groups, particularly between opposite occupational groups. Contrary to the overall trend, the level of managerial workers' residential separation from blue-collar workers and all other occupational groups has been growing, except for the period immediately following the collapse of the bubble economy in the early 1990s. Our findings highlight the significance of analyzing the changing patterns of residential segregation by finer occupational groups. We observed that managerial workers become even more spatially concentrated in central areas of 
Tokyo, which already had a high degree of their concentration. In contrast, professional and technical workers were increasingly concentrated in several areas in eastern Tokyo, an area that originally was not very specialized. From a spatial perspective, recent urban policies have developed unevenly and impacted neighborhood levels. Thus, managerial workers have been pushed into isolation, while there is an overall trend toward more intermingling. The top elite class' concentration in the city center is similar to that observed in London (Cunningham and Savage 2017), where the members of this class may segregate themselves from other groups in terms of socio-economic status and the spaces in which they live. Regarding spatial changes, studies have pointed out the phenomenon of "super-gentrification"; a more elite class moves into areas that have already been gentrified as observed in global cities such as New York (Lees 2003) and London (Butler and Lees 2006). These studies may provide useful references for understanding more detailed changes occurring in Tokyo. Because the intensification of residential segregation is assumed to harm the sustainable social environment of a city, much attention should be paid to the dynamics of socio-spatial division, especially between the top and the bottom social groups.

Further research should focus on the following aspects of residential segregation: First, our findings should be viewed from the comparative perspective of other cities and metropolitan areas, by leveraging quantitative segregation measures. By examining the segregation indices across cities or metropolitan areas within a country with the same criteria, we will be able to understand how our findings on Tokyo may be applied to another setting. Second, greater attention should be paid to the geographical scales of segregation because this study is limited in terms of spatial units. Lastly, future studies should investigate the consequences of the changes in socio-spatial segregation for urban residents.

\section{Acknowledgements}

I would like to express my gratitude to Prof. Maarten van Ham (Delft University of Technology) for valuable comments. This study was partly supported by a JSPS Grant-in-Aid for Scientific Research (B) and a Grant-inAid for JSPS Fellows.

\section{Notes}

1. Other reasons for focusing on the period until 2005 were related to the limitations of the dataset: a) in the 2010 census, the occu- pational classification used was revised considerably from before, and b) boundary data with a consistent geodetic reference system were not available after 2010 .

2. The Standard Occupational Classification for Japan was revised in 1986, 1997, and 2009. The occupational group used in this study is based on the revised version, which does not necessarily match the International Standard Classification of Occupations (ISCO) categories. "Mining worker" and "craftsman, production process worker, and laborer" in 1980/1985 and "craftsman, mining, manufacturing and construction workers, and laborer" in 1990/1995 were integrated into one category called "production process workers and laborers (PPW)" in 2000/2005.

3. In this study, each occupational group was categorized as part of a broad occupational group for the sake of convenience: whitecollar (MGR, P\&T, CLE), gray-collar (SAL, SER, T\&C), and bluecollar (PPW).

4. DI and $S I$ are expressed as follows, respectively:

$$
\begin{gathered}
D I=\frac{1}{2} \sum_{i}\left|\frac{x_{i}}{X}-\frac{y_{i}}{Y}\right| \\
S I=\frac{1}{2} \sum_{i}\left|\frac{x_{i}}{X}-\frac{t_{i}-x_{i}}{T-X}\right|
\end{gathered}
$$

where $x_{i}$ and $y_{i}$ are the populations in occupations $x$ and $y$, respectively, in district $i$; and $t_{i}$ is the total population of district $i$. Further, $X$ and $Y$ are the total populations in occupations $x$ and $y$ for the whole city, respectively. $T$ is the total population of the city.

5. $D, G, H$ and $C$ are expressed as follows, respectively:

$$
\begin{gathered}
D=\sum_{m} \sum_{j} \frac{t_{j}}{2 T I}\left|\pi_{j m}-\pi_{m}\right| \\
G=\sum_{m} \sum_{i} \sum_{j} \frac{t_{i} t_{j}}{2 T^{2} I}\left|\pi_{i m}-\pi_{j m}\right| \\
H=\sum_{j} \frac{t_{j}}{T E}\left(E-E_{j}\right) \\
C=\sum_{m} \sum_{j} \frac{t_{j}}{T} \frac{\left(\pi_{j m}-\pi_{m}\right)^{2}}{(M-1) \pi_{m}}
\end{gathered}
$$

where $t_{i}$ is the total population of district $i, T$ is the total population for a city as a whole, $\pi_{m}$ is the proportion in occupational group $m, \pi_{j m}$ is the proportion in occupational group $m$ in district $j$, and $M$ is the number of occupational group. Further, $I$ is Simpson's Interaction Index and $E$ is Theil's Entropy Index:

$$
\begin{gathered}
I=\sum_{m} \pi_{m}\left(1-\pi_{m}\right) \\
E=\sum_{m} \pi_{m} \ln \left(\frac{1}{\pi_{m}}\right)
\end{gathered}
$$

6. One grid square unit is treated as one district for this analysis.

7. $L Q$ in district $i$ is expressed as follows:

$$
L Q_{i}=\frac{x_{i} / t_{i}}{X / T}
$$

where $x_{i}$ and $t_{i}$ represent the population in occupation $x$ and total population, respectively, in district $i$. Further, $X$ and $T$ represent the population in occupations $x$ and the total population for the whole city, respectively.

8. $G^{*}$ in district $i$ is expressed as follows:

$$
G_{i}^{*}=\frac{\sum_{j} w_{i j} x_{j}-W_{i} \bar{x}}{s \sqrt{\left(n S_{1 i}-W_{i}^{2}\right) /(n-1)}}
$$

where $w_{i j}$ is a spatial weight between the district $i$ and neighboring district $j$. In this analysis, spatial relationship is based on contiguity (edges and corners). Moreover, $W_{i}$ is the sum of weights, $S_{1 i}$ 
is the sum of squared weights, $\bar{x}$ is the usual sample mean, $s^{2}$ is the sample mean variance, and $n$ is the total number of districts. The $G_{i}^{*}$ statistic indicates $z$-score value at district $i$ : The positive and large $z$-scores indicate the spatial clusters of high values (hot spots) while the negative and small $z$-scores indicate the spatial clusters of low values (cold spots).

9. The DIs of London (Madrid) in 2001 and 2011 were 0.39 and 0.41 (0.36 and 0.49$)$, respectively.

\section{References}

Aoi, S. and Nakazawa, T. 2014. Changes in the distribution of unmarried people living with parents and of blue-collar workers within the Tokyo metropolitan area: Application of the expansion method. E-journal GEO 9: 12-32. (JE)

Apparicio, P., Martori, J. C., Pearson, A. L., Fournier, E. and Apparicio, D. 2014. An open-source software for calculating indices of urban residential segregation. Social Science Computer Review 32: 117-128.

Brown, L. A. and Chung, S. Y. 2006. Spatial segregation, segregation indices and the geographical perspective. Population, Space and Place 12: 125-143.

Butler, T. and Lees, L. 2006. Super-gentrification in Barnsbury, London: Globalization and gentrifying global elites at the neighbourhood level. Transactions of the Institute of British Geographers 31: 467-487.

Cunningham, N. and Savage, M. 2017. An intensifying and elite city: New geographies of social class and inequality in contemporary London. City 21: 25-46.

Duncan, O. D. and Duncan, B. 1955. A methodological analysis of segregation indexes. American Sociological Review 20: 210-217.

Fielding, A. 2004. Class and space: Social segregation in Japanese cities. Transactions of the Institute of British Geographers 29: 64-84.

Fujita, K. and Hill, R. C. 2012. Residential income inequality in Tokyo and why it does not translate into class-based segregation. In Residential segregation in comparative perspective: Making sense of contextual diversity, ed. T. Maloutas and K. Fujita, 37-68. Farnham: Ashgate.

Fujitsuka, Y. 2013. Gentrification in London, New York and Tokyo. Japan Society for Urbanology Annual Report 47: 277-282. (J)

Hashimoto, K. 2011. Kaikyu toshi. Tokyo: Chikuma shobo. (J)

Hashimoto, K. and Asakawa, T. 2020. Kakusashakai to toshikukan. Tokyo: Kajima Institute Publishing. (J)

Ichida, Y., Kondo, K., Hirai, H., Hanibuchi, T., Yoshikawa, G. and Murata, C. 2009. Social capital, income inequality and selfrated health in Chita peninsula, Japan: A multilevel analysis of older people in 25 communities. Social Science \& Medicine 69: 489-499.

Jacobs, A. J. 2005. Has central Tokyo experienced uneven development? An examination of Tokyo's 23 ku relative to America's largest urban centers. Journal of Urban Affairs 27: 521-555.

Jacobs, A. J. 2012. The nested global city-region: Intermunicipal income stratification in the Tokyo Metropolitan Region, 1980-2007. Urban Geography 33: 120-146.

Koizumi, R. 2010. Spatial patterns of occupational structure and their changes in Tokyo metropolitan area. Quarterly Journal of Geography 62: 61-70. (JE)

Koizumi, R. 2015. Occupational structure in the Tokyo metropolitan area, 1985-2005: An extended shift-share analysis of changing geographic patterns. In Urban geography of postgrowth society, ed. M. Hino and J. Tsutsumi, 61-75. Sendai: Tohoku University Press.

Koizumi, R. and Wakabayashi, Y. 2015. Changes in the spatial patterns of occupational structure in the Tokyo metropolitan area after the bubble economy. In Urban development challenges, risks and resilience in Asian mega cities. Advances in geographical and environmental sciences, ed. R. Singh, 351-366. Tokyo: Springer.

Kubo, T. 2020. Divided Tokyo: Disparities in living conditions in the city center and the shrinking suburbs. Singapore: Springer.

Kurasawa, S. ed. 1986. Social atlas of Tokyo. Tokyo: University of Tokyo Press. (J)

Kurasawa, S. and Asakawa, T. eds. 2004. New social atlas of metropolitan Tokyo: 1975-90. Tokyo: University of Tokyo Press. (J)

Lees, L. 2003. Super-gentrification: The case of Brooklyn Heights, New York City. Urban Studies 40: 2487-2509.

Lützeler, R. 2008. Population increase and "new-build gentrification" in central Tokyo. Erdkunde 62: 287-299.

Maloutas, T. and Fujita, K. eds. 2012. Residential segregation in comparative perspective: Making sense of contextual diversity. Farnham: Ashgate.

Marcińczak, S., Tammaru, T., Novak, J., Gentile, M., Kovács, Z., Temelová, J., Valatka, V., Kährik, A. and Szabó, B. 2015. Patterns of socioeconomic segregation in the capital cities of fast-track reforming postsocialist countries. Annals of the Association of American Geographers 105: 183-202.

Massey, D. S. 1996. The age of extremes: Concentrated affluence and poverty in the twenty-first century. Demography 33: 395412.

Miyazawa, H. and Abe, T. 2005. Recovery and changes in the socioeconomic composition of population in the central area of Tokyo during the period from 1995 to 2000: Analysis of small-area census data. Geographical Review of Japan 78: 893912. (JE)

Morgan, B. S. 1975. The segregation of socio-economic groups in urban areas: A comparative analysis. Urban Studies 12: 47-60.

Murayama, H., Arami, R., Wakui, T., Sugawara, I. and Yoshie, S. 2014. Cross-level interaction between individual and neighbourhood socioeconomic status in relation to social trust in a Japanese community. Urban Studies 51: 2770-2786.

Musterd, S., Marcińczak, S., van Ham, M. and Tammaru, T. 2017. Socioeconomic segregation in European capital cities: Increasing separation between poor and rich. Urban Geography 38: 1062-1083.

Nakazawa, T. 2016. Residential differentiation in the Tokyo metropolitan area in terms of occupation-specific net migration. Annals of the Association of Economic Geographers 62: 39-56. (JE)

Ord, J. K. and Getis, A. 1995. Local spatial autocorrelation statistics: Distributional issues and an application. Geographical Analysis 27: 286-306.

R Core Team 2018. R: A language and environment for statistical computing. Vienna: R Foundation for Statistical Computing. 
Reardon, S. and Bischoff, K. 2011. Income inequality and income segregation. American Journal of Sociology 116: 1092-1153.

Reardon, S. and Firebaugh, G. 2002. Measures of multigroup segregation. Sociological Methodology 32: 33-67.

Sampson, R. J., Morenoff, J. D. and Gannon-Rowley, T. 2002. Assessing "neighborhood effects": Social processes and new directions in research. Annual Review of Sociology 28: 443478.

Sassen, S. 2001. The global city: New York, London, Tokyo, 2nd ed. Princeton: Princeton University Press.

Sonobe, M. 2001. Contemporary metropolitan society: Dual city? Tokyo: Toshindo. (J)

Tammaru, T., van Ham, M., Marcińczak, S. and Musterd, S. eds. 2016. Socio-economic segregation in European capital cities: East meets west. London and New York: Routledge.

Toyoda, T. 1999. The changing spatial structure of a world city, Tokyo: An aspect of social polarization. Journal of human sciences and arts, Faculty of Integrated Arts and Sciences, the University of Tokushima 6: 123-139. (J)

Toyoda, T. 2007. Social polarization and socio-spatial structure of metropolitan areas: A comparative analysis of income inequality in Tokyo, Osaka and Nagoya. The Annals of Japan Association for Urban Sociology 25: 5-21. (JE)

Toyoda, T. 2011. Spatial structure of income inequality in metropolitan city: A comparative analysis of Tokyo and Osaka. Japan Society for Urbanology Annual Report 44: 219-226. (JE)

Toyoda, T. 2012. Regional income inequality and spatial structure of metropolitan area: Analysis on municipal differentials in household income. Journal of human sciences and arts, Faculty of Integrated Arts and Sciences, the University of Tokushima 20: 51-62. (J)

Ueno, J. 2008. The impact of deregulation and urban development: Socio-spatial polarization in Tokyo. The Annals of Japan Association for Urban Sociology 26: 101-115. (JE)

Uesugi, M. 2019. Socioeconomic segregation and its structural factors in Japanese metropolitan areas. Urban Housing Sciences 107: 76-81. (JE)

van Ham, M., Manley, D., Bailey, N., Simpson, L. and Maclennan, D. eds. 2012. Neighbourhood effects research: New perspectives. Dordrecht: Springer.

van Ham, M., Uesugi, M., Tammaru, T., Manley, D. and Janssen, H. 2020. Changing occupational structures and residential segregation in New York, London and Tokyo. Nature Human Behaviour 4: 1124-1134.

Wakabayashi, Y. and Koizumi, R. 2014. Spatial patterns of population change in the 23 special wards of Tokyo after the period of the bubble economy. Journal of Geography (Chigaku Zasshi) 123: 249-268. (JE)

Watson, T. 2009. Inequality and the measurement of residential segregation by income in American neighborhoods. Review of Income and Wealth 55: 820-844.

Waley, P. 2013. Pencilling Tokyo into the map of neoliberal urbanism. Cities 32: 43-50.

Yabe, N. 2003. Population recovery in inner Tokyo in the late 1990s: A questionnaire survey in Minato Ward. Japanese Journal of Human Geography 55: 277-292. (JE)

(J) written in Japanese

(JE) written in Japanese with English abstract 